\title{
SUCCESS OF CONSERVATIVE TREATMENT OF TRIGGER THUMB IN CHILDREN AFTER MINIMUM FOLLOW-UP OF FIVE YEARS
}

Edilson Forlin', Ellen Yuri Kaetsu², José Eduardo Eid de Vasconcelos ${ }^{3}$

\section{ABSTRACT}

Objective: The aim of this study was to evaluate the outcome of conservative treatment of trigger thumb in children, in order to discuss the real need for surgical release in these patients. Methods: This was a retrospective study on a group of children with trigger thumb who were treated conservatively by the same orthopedic surgeon with gentle manipulation at the time of the consultation and guidance on stretching to be performed at home. The cases were followed up for at least five years. Results: Thirteen thumbs in 11 children (seven boys and four girls) were treated. The mean age at the first consultation was 26.3 months (range: 11 to 36 months). The mean follow-up was 10 years (range: 5 to
16 years). Ten thumbs showed satisfactory results $(77 \%)$ : eight of these were diagnosed when the child was younger than two years of age. The mean time taken from diagnosis to clinical improvement was 20.8 months (range: 6 to 36 months). The three thumbs that required surgical treatment were diagnosed after the age of two years and six months. Conclusions: Conservative treatment of trigger thumb in children showed a high rate of success, especially in children who were diagnosed up to the age of two years. This is important information to be passed on to parents and may avoid unnecessary surgery in many cases.

Keywords - Trigger Finger Disorder; Child; Retrospective Studies

\section{INTRODUCTION}

Trigger finger, or stenosing tenosynovitis, is a common disorder in children with an estimated prevalence of $2.2 \%$, among all upper-limb deformities ${ }^{(1)}$. The thumb is affected around ten times more frequently than the other fingers ${ }^{(2)}$. Trigger thumb occurring alone has not been correlated with any syndromes, but other fingers with trigger deformity have been correlated with neurological syndromes such as trisomy 18 and mucopolysaccharidosis ${ }^{(3)}$.

It is believed that the pathological abnormality is due to thickening of the tendon sheath and consequent nodule formation, which obstructs the sliding mechanism of the A1 pulley and causes deformity of the interphalangeal joint in a flexed position ${ }^{(4)}$. The etiology has been attributed to congenital factors ${ }^{(5-8)}$ or traumatic factors ${ }^{(9-13)}$.

Regarding treatment, many authors have recom- mended early surgical release. According to studies by Sprecher ${ }^{(9)}$ and Kim and Noonan ${ }^{(14)}$, conservative approaches have unsatisfactory results, while surgical treatment is considered to provide definitive treatment. In the same way, Herring ${ }^{(15)}$ established that pulley release was essential, and Waters ${ }^{(3)}$ considered that the treatment of choice was surgical, if there was no improvement by the age of one year.

Other authors have observed spontaneous resolution of trigger thumb. Kozin ${ }^{(16)}$ cited the possibility of improvement through conservative treatment, but without specifying a period of observation time before indicating surgery. Dinham and Meggitt ${ }^{(17)}$ found that $30 \%$ of trigger thumb cases resolves spontaneously when diagnosed by the age of one year. In a study with length of follow-up ranging from seven months to 12 years, Sugimoto ${ }^{(18)}$ observed improvements in more than one third of the patients. More recently,

1 - MD (Orthopedics), MSc and PhD from Unifesp. Orthopedist at Hospital Pequeno Príncipe, Curitiba, PR, Brazil

2 - Third-year Resident at Hospital Pequeno Príncipe XV, Curitiba, PR, Brazil.

3 - Third-year Resident at Hospital Santa Casa de Curitiba, Curitiba, PR, Brazil.

Work performed at Hospital Pequeno Príncipe, Curitiba, PR.

Correspondence: Ellen Yuri Kaetsu, Rua Buenos Aires 1020, Água Verde, 80250-070 Curitiba, PR. E-mail: ediforlin@hotmail.com

Work received for publication: September 21, 2011; accepted for publication: November 10, 2011.

The authors declare that there was no conflict of interest in conducting this work 
Baek et al ${ }^{(19)}$ observed spontaneous complete resolution in $63 \%$ of their 71 cases of trigger thumb, and most of the remaining cases presented partial improvement of the deformity.

Despite these published data, many orthopedists in our setting still do not consider conservative treatment to be an option and even indicate surgery at the first assessment on these patients. The objectives of this study were to assess the results from conservative treatment in children and discuss the real need for surgical release.

\section{MATERIALS AND METHODS}

This was a retrospective study in which data were gathered on children with a diagnosis of trigger thumb who had been treated consecutively by the senior author (EF) using a specific conservative method, between April 1995 and July 2006.

The inclusion criteria for this study were: concordance with a consent statement, diagnosis of trigger thumb no later than the age of three years and ability to contact the patients again, at least five years after the first assessment. The exclusion criteria were the presence of other associated syndromic, genetic or neuromuscular conditions, refusal to participate in the study and subsequent surgical treatment less than one year after the conservative treatment.

This study was approved by the Ethics Committee for Research Involving Human Beings, of Hospital Pequeno Príncipe, in accordance with resolution no. 196/96 of the National Health Council. The information in the present study was obtained through acceptance of a consent statement by the patients' parents.

The conservative treatment consisted of gentle and patient stretching of the trigger finger, so as to reduce the condition by the time of the orthopedist's assessment. The adults responsible for doing this were instructed to make daily observations and perform the stretching if they noticed that the thumb had gone back to a flexed position. A return visit was scheduled to take place six months later, or earlier if the deformity reappeared and the family were unable to reduce it. In reviewing the medical files, epidemiological data on the patients were gathered and contact with the parents was established so that a questionnaire could be filled in (Annex 1).

The result was considered to be satisfactory when the deformity had been corrected, either totally (complete normalization of movement, without situations of blockage) or partially (if the parents reported that sporadic joint blockage was present, but without any functional deficit). Unsatisfactory results were situations of persistence of the deformity, with the need for surgery.

\section{RESULTS}

The medical files of 15 children treated in accordance with the abovementioned criteria were reviewed. In three cases, it was not possible to contact the patients for the questionnaire to be filled in. In addition, one of the children was excluded because surgical treatment had been chosen less than six months after the diagnosis. There were no refusals to participate in the study.

Consequently, 11 children were included in the study, with 13 thumbs involved (two cases were bilateral). Seven were boys and four were girls, with a mean age at the first consultation of 26.3 months (ranging from 11 to 36 months). The mean length of follow-up was 10 years (ranging from five to 16 years).

Out of the 13 thumbs treated, satisfactory results were achieved in 10 cases (77\%), among which seven were considered to be total correction and three, partial improvement (Figure 1). The mean length of time from the diagnosis to the improvement was 20.8 months (ranging from six to 36 months). Among the 13 trigger thumbs, eight were diagnosed before the age of 24 months, and satisfactory results were achieved in all of these cases. Among the five cases in patients who were over the age of 24 months at the time of diagnosis, satisfactory results were only achieved in two cases.

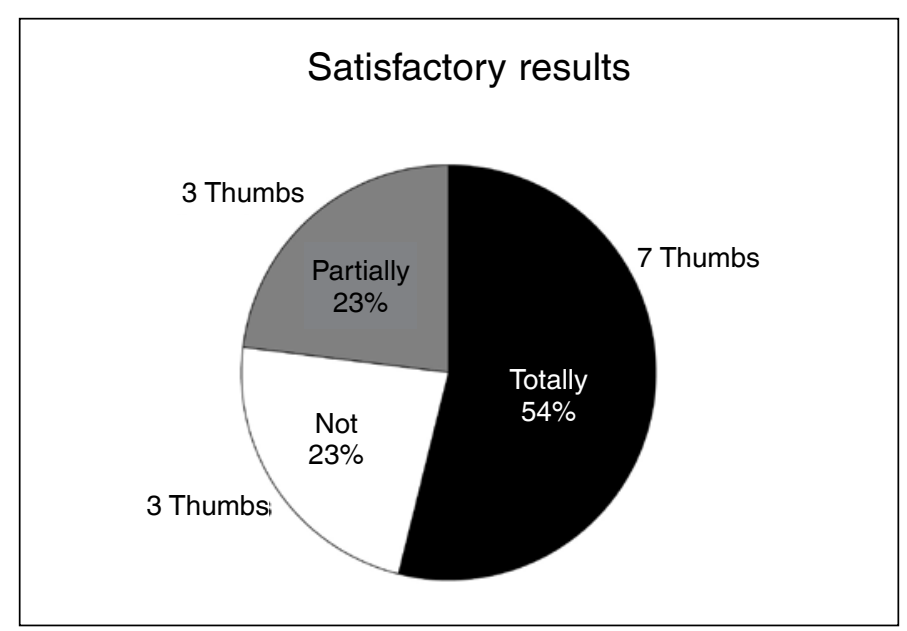

Figure 1 - Percentages of totally or partially satisfactory results and unsatisfactory results. 
Three patients with unsatisfactory results underwent surgical treatment. These children were 30 , 36 and 36 months of age at the time of the diagnosis, and underwent operations 36, 12 and 12 months after the first consultation, respectively (Figure 2, Table 1).

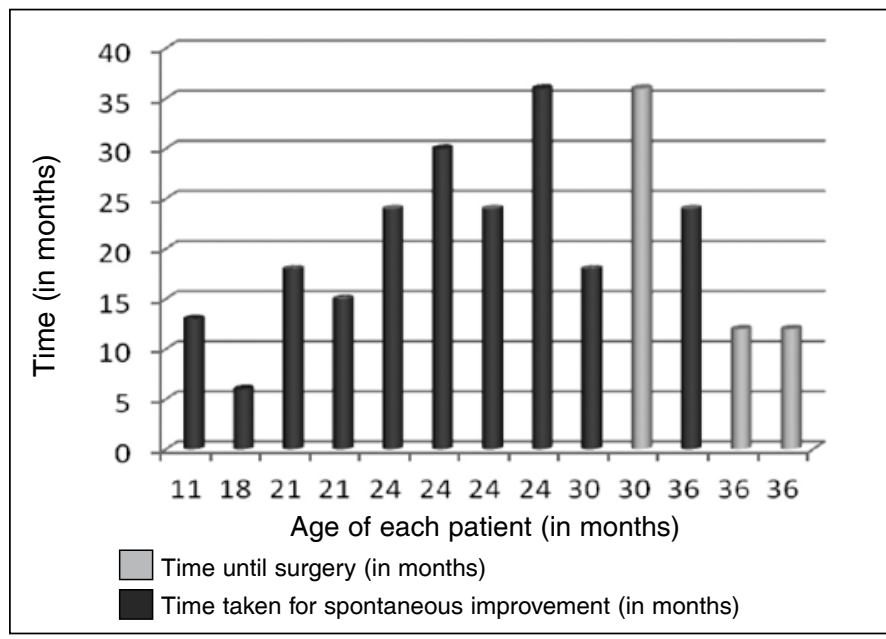

Figure 2 - Patient distribution according to age, in months. In black, the time in months taken to reach spontaneous improvement is shown. In grey, the time in months until surgery is shown.

Tabela 1 - Relação dos pacientes conforme sexo, idade, tempo para a melhora espontânea ou para a cirurgia (em meses).

\begin{tabular}{c|c|c|c|c}
\hline Patient & Sex & $\begin{array}{c}\text { Age } \\
\text { (months) }\end{array}$ & $\begin{array}{c}\text { Time taken for } \\
\text { spontaneous improvement } \\
\text { (in months) }\end{array}$ & $\begin{array}{c}\text { Time until } \\
\text { surgery } \\
\text { (in months) }\end{array}$ \\
\hline 1 & $\mathrm{M}$ & 11 & 13 & 0 \\
\hline 2 & $\mathrm{~F}$ & 18 & 6 & 0 \\
\hline 3 & $\mathrm{M}$ & 21 & 18 & 0 \\
\hline 4 & $\mathrm{M}$ & 21 & 15 & 0 \\
\hline 5 & $\mathrm{M}$ & 24 & 24 & 0 \\
\hline 6 & $\mathrm{~F}$ & 24 & 30 & 0 \\
\hline 7 & $\mathrm{M}$ & 24 & 24 & 0 \\
\hline 8 & $\mathrm{M}$ & 24 & 36 & 0 \\
\hline 9 & $\mathrm{M}$ & 30 & 18 & 0 \\
\hline 10 & $\mathrm{M}$ & 30 & 0 & 36 \\
\hline 11 & $\mathrm{M}$ & 36 & 24 & 0 \\
\hline 12 & $\mathrm{~F}$ & 36 & 0 & 12 \\
\hline 13 & $\mathrm{~F}$ & 36 & 0 & 12 \\
\hline
\end{tabular}

\section{DISCUSSION}

Trigger thumb is a common entity with a simple clinical diagnosis. However, aspects of its natural history, evolution and, especially, indications for treatment are not fully known by orthopedists.

Many authors have only taken surgical treatment into consideration. Cortez et $\mathrm{al}^{(20)}$ conducted a retrospective study covering 2005 to 2009 , to evaluate congenital malformations found in the city of Recife, and observed that $5 \%$ (12 children) presented trigger finger, and that surgery was indicated in all these cases. Likewise, in a study published by Fukushima et al ${ }^{(21)}$, surgical treatment was performed on 25 children aged one to six years, without any attempt to implement conservative treatment prior to this.

In the Guidelines Project of 2009, from the Brazilian Medical Association and the Brazilian Society of Orthopedics and Traumatology, surgical release is indicated for patients over the age of three years for whom conservative treatment has not achieved resolution, but it may even be indicated for children after they reach the age of one year ${ }^{(22)}$. In the study by Mattar Júnior ${ }^{(23)}$, several forms of treatment were cited, among which conservative treatment was only given preference in mild cases with intermittent symptoms. Chakkour ${ }^{(24)}$ stated that conservative treatment was possible up to the age of two years, with $70 \%$ improvement when done with massage and physiotherapy. However, that author also stated that when blockage of movement occurred, surgical correction was overwhelmingly indicated. Pardini Júnior et $\mathrm{al}^{(25)}$ stated that the treatment in the initial phase should consist of infiltration and rest, and recommended surgery for the chronic phase. It is unclear from their text whether this recommendation is only for adult patients, or whether it also applies to the pediatric population.

Many studies worldwide have also recommended surgical release. Fahey and Bollinger ${ }^{(5)}$ reported that conservative treatment led to failure in practically all their patients and therefore they recommended surgical treatment. Sprecher ${ }^{(9)}$ also demonstrated that conservative treatment produced unsatisfactory results, and that surgical release was indicated. Kim and Noonan ${ }^{(14)}$ considered that surgical treatment was the definitive method, thereby avoiding persistent contractures, particularly among patients over

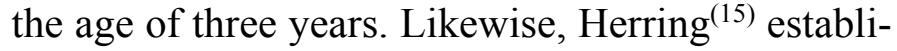
shed that pulley release was essential for achieving full mobility and for avoiding recurrences. Waters ${ }^{(3)}$ reported that spontaneous improvement occurred in fewer than $10 \%$ of the patients over the age of one year and, for this reason, considered surgery to be the treatment of choice.

We must emphasize that although surgery is simple, it is an invasive procedure that requires general anesthesia and hospitalization ${ }^{(2,13)}$. Fukushima et $\mathrm{al}^{(26)}$ presented 35 trigger thumbs that were operated, among which one presented superficial skin infection and two, partial dehiscence of the suture. In the study by Dunsmuir and Sherlock ${ }^{(27)}$, out of the 
166 thumbs operated, three presented superficial infection and eight presented recurrence. Recurrence is generally secondary to inadequate release of the flexor tendon sheath ${ }^{(16)}$.

However, in contrast with the abovementioned studies, other studies have demonstrated that trigger thumb can resolve spontaneously or with conservative treatment. According to Dinham and Meggitt ${ }^{(17)}$, children diagnosed at ages between six and 30 months can safely be kept under observation for a minimum period of six months, since the spontaneous resolution rate was $12 \%$. Moreover, these authors stated that surgical release performed up to the age of four years should not cause residual interphalangeal contractures. Likewise, Mulpruek and Prichasuk ${ }^{(28)}$ found that 10 cases spontaneously resolved, among 42 patients followed up for a period of only three months, and they took the view that observation up to the age of three years would not impair the final result.

One form of conservative treatment can consist of using a polypropylene splint to stabilize the interphalangeal joint at its maximum extension. Using this approach, Nemoto et $\mathrm{al}^{(29)}$ treated 43 trigger thumbs, and 24 of these cases resolved completely within 10 months after the diagnosis, seven improved and two required surgery. According to Lee et $\mathrm{al}^{(30)}$, the correction obtained through using an orthosis was more than three times greater than what was observed using observation alone (38.7 and $12.9 \%$, respectively). Pechora $^{(31)}$ reported that corticoid infiltration produced satisfactory results among children under the age of three years, even though this procedure is little indicated among children.

Watanabe et $\mathrm{al}^{(32)}$ studied 58 cases of trigger thumb for which the advice was that passive exercises should be performed by the patients' mothers, and reported that satisfactory results were obtained in the cases of 54 thumbs (96\%). Among patients under the age of three years, surgery was only indicated for cases of greater deformity. In a study on 71 trigger thumbs treated with massage or splints, Baek et $\mathrm{al}^{(19)}$ found

\section{REFERENCES}

1. Flatt $A E$. The care of congenital hand anomalies. 2nd ed. St. Louis: Quality Medical Publishing; 1994. p. 59-60.

2. Cardon LJ, Ezaki M, Carter PR. Trigger finger in children. J Hand Surg Am.1999;24(6):1156-61.

3. Waters PM. Trigger thumb. In: Lovell and Winter's pediatric orthopedics. 6th ed. Philadelphia: Lippincott-Raven; 2008. p. 960.

4. Camargo D, Angelini LC, Oliveira MT, Sawaeda DM. Estudo prospectivo do tratamen- that $63 \%$ of the cases achieved total spontaneous resolution and $30 \%$, partial resolution.

In the present study, the orthopedist performed gentle reduction of the thumb in the consultation office and the patients were advised to perform stretching at home. These results corroborate the most recently published studies, since the success rate obtained was $77 \%$ among the 13 thumbs. The patients who underwent surgery were observed for a minimum period of one year (one patient followed up for one year and two for three years). These children presented older chronological ages at the time of the diagnosis (30, 36 and 36 months).

Despite concordance with other published studies, the present study is limited by the small number of patients studied and the need for subjective assessment by the parents regarding the amount of improvement of the deformity.

The importance of this study was that it had a group that was assessed, guided and followed up uniformly by a single orthopedist. A very suitable length of follow-up was achieved (minimum of five years), which allowed it to be said that there were no cases of recurrence. Our data strengthen the idea that there is a clear possibility of resolution of trigger thumb without the need for surgery. This information should be given to parents in help in deciding on the approach to take. Another important factor in choosing the treatment is that if the thumb continues to present the trigger deformity up to an age of at least four years, this should not cause any functional harm or compromise the final result, and the surgical treatment can be performed after this age.

\section{CONCLUSION}

This study demonstrates that conservative treatment of trigger thumb presents a high rate of satisfactory results, especially among children diagnosed up to the age of two years. With this approach, invasive procedures that are subject to complications can be avoided for many children. to conservador do dedo em gatilho- avaliação de 131 dedos. Einstein. 2009;7:76-80.

5. Fahey JJ, Bollinger JA. Trigger-finger in adults and children. J Bone Joint Surg Am. 1954;36(6):1200-18.

6. Neu BR, Murray JF. Congenital bilateral trigger digits in twins. J Hand Surg Am. 1983;8(3):350-2.

7. Thomas SR, Dodds RD. Bilateral trigger thumbs in identical twins. J Pediatr Orthop B. 1999;8(1):59-60. 
8. Kakel R, Heerden PV, Gallagher B, Verniquet A. Pediatric Trigger Thumb in Identical Twins: congenital or acquired? Orthopedics. 2010;33(3):205-8.

9. Sprecher EE. Trigger thumb in infants. J Bone Joint Surg Am. 1949;31(3):672-4.

10. Rodgers WB, Waters PM. Incidence of trigger digits in newborns. J Hand Surg Am. 1994;19(3):364-8.

11. Kikuchi N, Ogino T. Incidence and development of trigger thumb in children. $\mathrm{J}$ Hand Surg Am. 2006;31(4):541-3.

12. Moon WN, Suh SW, Kim IC. Trigger digits in children. J Hand Surg Br. 2001;26(1):11-2.

13. Slakey JB, Hennrikus WL. Acquired thumb flexion contracture in children:congenital trigger thumb. J Bone Joint Surg Br. 1996;78(3):481-3.

14. Kim Y, Noonan KJ. What's new in pediatric orthopaedics. J Bone Joint Surg Am. 2009;91(3):743-51

15. Herring JA. Disorders of the upper extremity. In:Tachdjian's pediatric orthopaedics. 4th ed. Philadephia: Saunders; 2008. p. 578-9.

16. Kozin SH. Deformities of the thumb. In: Green's operative hand surgery. 6th ed. Philadelphia: Elsevier. 2010. p. 1397-9.

17. Dinham JM, Meggitt BF. Trigger thumbs in children. A review of the natural history and indications for treatment in 105 patients. J Bone Joint Surg Br. 1974;56(1):153-5.

18. Sugimoto Y. Treatment of trigger digit in children. Seikei Geka. 1991;34:1047-50.

19. Baek GH, Kim JH, Chung MS, Kang SB, Lee YH, Gong HS. The natural history of pediatric trigger thumb. J Bone Joint Surg Am. 2008;90(5):980-5.

20. Cortez M, Silva RF, Gilbert A, Brandt CT, Valenti P. Nosologia das doenças da mão de crianças e jovens operados em mutirões realizados em hospital de referência no estado de Pernambuco. Rev Bras Ortop. 2010;45(5):445-52.

21. Fukushima WY, Fujiki EN, Ruggiero GM, Cho AB, Aita MA, Nascimento FP, et al. Diagnóstico precoce e o tratamento cirúrgico do polegar em gatilho congênito na criança utilizando o sistema de internação hospital-dia. Arq Bras Cienc Saúde. 2009;35(1):24-7.

22. Sternick MB, Pires RES. Projeto Diretrizes Clínicas na Saúde Suplementar. São Paulo: AMB e SBOT; 2009.

23. Mattar Júnior R. Tenossinovite estenosante dos flexores ou dedo em gatilho. Einstein. 2008;6(1):S145-5.

24. Chakkour I. Defeitos congênitos do membro superior. In: SBOT Ortopedia Pediátrica; 2004. p. 302.

25. Pardini Júnior AG, Freitas AD, Tavares KE. Antebraço, punho e mão. In: Herbert S, Barros Filho TEP, Xavier R, Pardini Júnior AG. Tratado de ortopedia e traumatologia: princípios e prática. 4a ed. Porto Alegre: Artmed; 2009. p.244.

26. Fukushima WY, Fujiki EN, Milani C, Nicolau RJ, Valesin E, Mattar TGM. Polegar em gatilho congênito ou tenossinovite estenosante do polegar em criança [tema livre]. In: $36^{\circ}$. Conresso Brasiliero de Ortopedia e Traumatologia, Rio de Janeiro, 2004.

27. Dunsmuir RA, Sherlock DA. The outcome of treatment of trigger thumb in children. J Bone Joint Surg Br. 2000;82(5):736-8.

28. Mulpruek $P$, Prichasuk $S$. Spontaneous recovery of trigger thumbs in children. J Hand Surg Br. 1998;23(2):255-7.

29. Nemoto K, Nemoto T, Terada N, Amako M, Kawaguchi M. Splint therapy for trigger thumb and finger in children. J Hand Surg Br. 1996;21(3):416-8.

30. Lee ZL, Chang $\mathrm{CH}$, Yang WY, Hung SS, Shih $\mathrm{CH}$. Extension splint for trigger thumb in children. J Pediatr Orthop. 2006;26(6):785-7.

31. Pechora TA. Use of hydrocortisone in treating stenotic tendovaginitis of the fingers in children. Vestn Khir Im I I Grek. 1985;134:97-9.

32. Watanabe $\mathrm{H}$, Hamada $\mathrm{Y}$, Toshima T, Nagasawa K. Conservative treatment for trigger thumb in children. Arch Orthop Trauma Surg. 2001;121(7):388-90.

Annex 1 - Protocol for trigger thumb.

Name:

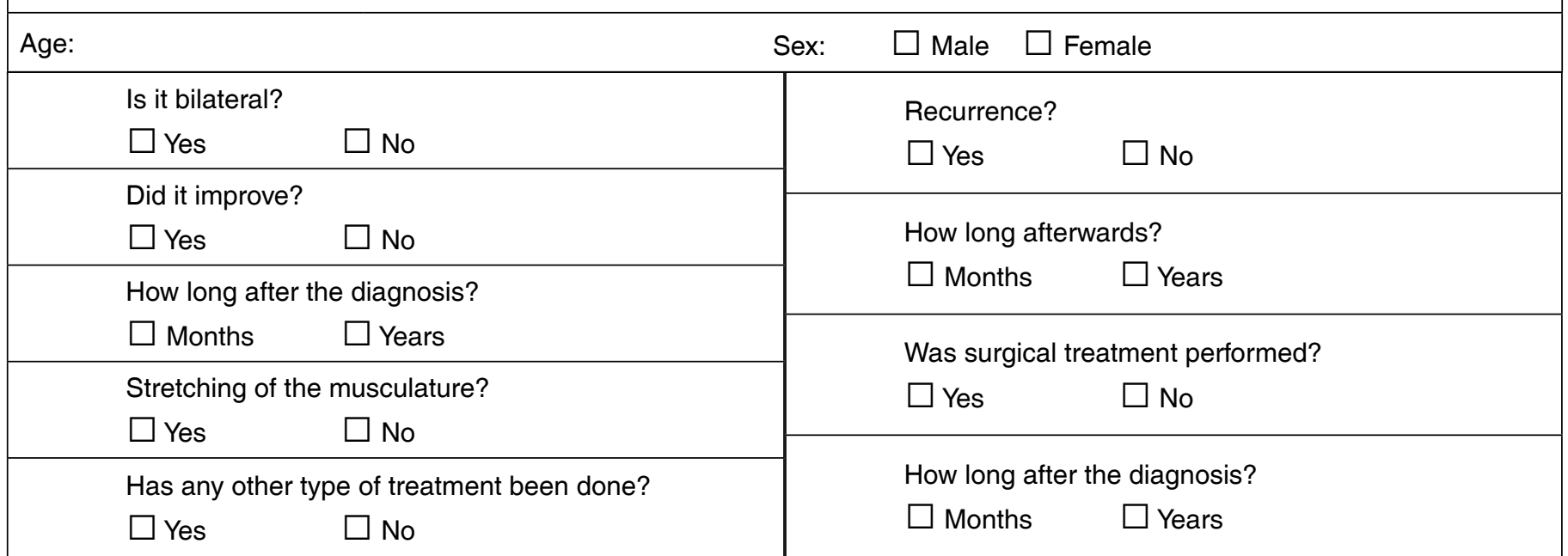

